Interactive comment on "Formation and sink of glyoxal and methylglyoxal in a polluted subtropical environment: observation-based photochemical analysis and impact evaluation" by Zhenhao Ling et al.

\title{
Zhenhao Ling et al.
}

lingzhh3@mail.sysu.edu.cn

Received and published: 21 July 2020

Interactive comment on "Formation and sink of glyoxal and methylglyoxal in a polluted subtropical environment: observation-based photochemical analysis and impact evaluation" by Zhenhao Ling et al. Zhenhao Ling et al. lingzhh3@mail.sysu.edu.cn

Response to Reviewers

Reviewer \#2 The paper investigates the importance of glyoxal (GLY) and methylglyoxal 
SOA formation has been previously studied but this study investigated several different methods of modeling GLY and MGLY SOA, which provides additional information on how to model this important process. I have a few suggestions for the authors when they revise their paper: Reply: Thank a lot for the reviewer's positive comments and helpful suggestions. We have addressed all the comments/suggestions in the revised manuscript. Detailed responses to the individual specific comment/suggestion are as follows. All the revision is highlighted in the revised manuscript.

1. The gas-phase concentrations of $\mathrm{OH} / \mathrm{HO} 2$ are not constrained in the box model simulations. Instead, they are calculated using the box model. However, GLY and MGLY can be removed in the gas phase reactions with $\mathrm{OH}$. Thus, it is necessary to evaluate the predicted $\mathrm{OH} / \mathrm{HO} 2$ concentrations to make sure the competing between gas/particle partitioning, which forms SOA, and the gas phase decay processes that reduce the SOA formation is correctly captured. Reply: The reviewer's comment is highly appreciated. In this study, the $\mathrm{OH}$ and $\mathrm{HO} 2$ radicals were simulated based on the measured mixing ratios of $\mathrm{O} 3, \mathrm{NOx}, \mathrm{CO}$, and $\mathrm{NMHCs}$, together with meteorological parameters, as the direct measurement of $\mathrm{OH}$ and $\mathrm{HO} 2$ radical was not available (Xue et al., $2014 \mathrm{a}, \mathrm{b})$. Furthermore, the photolysis rates adopted in the model were determined from the photon fluxes from the Tropospheric Ultraviolet and Visible Radiation (TUV-v5) model (Madronich and Flocke 1997) according to the sampling location and modeling period. Previous studies have demonstrated that the observation-based model coupled with Master Chemical Mechanism (MCM), such as the PBM-MCM model in the present study, could perform well in the simulation of $\mathrm{O} 3$, photochemical reactivities and atmospheric radical chemistry (e.g., the budgets, variations of $\mathrm{OH}$ and $\mathrm{HO} 2$ radicals and contributions from varied production and destruction pathways) in different environments/regions in China (Huang et al., 2020 and references therein; Ling et al., 2014; Liu et al., 2019; Wang et al., 2018; Xue et al., 2014a, b; Yang et al., 2018). To better evaluate the model performance on the simulation of $\mathrm{OH}$ and $\mathrm{HO} 2$ abundance and variations, we also compared our simulation results with the previous observations conducted in PRD and other regions in the world (Table 1 as seen below). In this 
study, the simulation on the diurnal variations of $\mathrm{OH}$ and $\mathrm{HO} 2$ was performed well, with peak values at noon, consistent with those measured and simulated in PRD (Hofzumahaus et al., 2009 and related papers; Tan et al., 2019). The simulated mean mixing ratios of $\mathrm{OH}$ and $\mathrm{HO} 2$ radicals from the model in the present study were $\sim 1.6 \times 106$ moleculeÂůcm-3 and $\sim 3 \times 107$ moleculeÂůcm-3, which are comparable to the winter observations at Beijing, Tokyo, and New York (Kanaya et al., 2007; Ren et al., 2006; Ma et al., 2019), and lower than the measurement and simulation values in summer (e.g., July) or autumn (e.g., October to November) in the PRD region (Table S3 in the supplementary) (Hofzumahaus et al., 2009; Tan et al., 2019). Note that the variations of simulation results in the present study and those observation results in previous studies in PRD may be associated with differences in the levels of $\mathrm{O} 3$ and its precursors, different photolysis rates, and to a lesser extent, meteorological conditions (Hofzumahaus et al., 2009). The higher $\mathrm{OH}$ and $\mathrm{HO} 2$ mixing ratios were expected in summer and autumn than winter due to the stronger solar radiation and higher temperature, as well as the variations of $\mathrm{O} 3$ and its precursors in different sites, though the measurement of $\mathrm{OH} / \mathrm{HO} 2$ radicals has been very challenging, and significant uncertainties still exist in the measurement values of the radicals (Hofzumahaus et al., 2009; Tan et al., 2019). Furthermore, the comparison between the simulation of a box model and observation results suggested that the higher observed mixing ratios of $\mathrm{OH}$ and $\mathrm{HO} 2$ radicals were related to an unidentified source of $\mathrm{OH}$ at the backgarden site of PRD in summer of 2006, while the comparison between the observed $\mathrm{OH} / \mathrm{HO} 2$ variations and those calculated from the parameterization of $\mathrm{HOx}(\mathrm{HOx}=\mathrm{OH}+\mathrm{HO} 2)$ production and destruction indicated a missing $\mathrm{OH}$ source of 4-6 ppbvÂůh-1 and an unknown $\mathrm{RO} 2$ loss at the Heshan site in autumn of 2014. Overall, the above comparison suggested that the model simulation for the variations of $\mathrm{OH}$ and $\mathrm{HO} 2$ radicals, and related atmospheric photochemical reactivities was appropriate at Heshan in this study.

Table 1 The mean measured $\mathrm{OH}$ and $\mathrm{HO} 2$ concentrations in the previous studies and our model results (in molecule cm-3) Location season $\mathrm{OH}(\times 106) \mathrm{HO} 2(\times 108)$ year Reference PRD, China Summer 15 - 2006 (Hofzumahaus et al., 2009) Shanghai, China 
10.2 - 2013 (Nan et al., 2017) north-western Greece 84.71997 (Creasey et al., 2001) PRD, China Autumn 4.53 .02014 (Tan et al., 2019) Tokyo, Japan Winter 1.5 - 2004 (Kanaya et al., 2007)

New York, America 1.4 - 2004 (Ren et al., 2006)

Interactive

Beijing, China 1.50 .32017 (Ma et al., 2019)

PRD, China 1.6 0.3 2017 This study

To clarify the model performance on the simulation of $\mathrm{OH}$ and $\mathrm{HO} 2$ abundance and variations, the above analysis and comparison have been added in the revised manuscript: "In this study, the simulation on the diurnal variations of $\mathrm{OH}$ and $\mathrm{HO} 2$ was performed well, with peak values at noon, consistent with those measured and simulated in PRD (Hofzumahaus et al., 2009 and related papers; Tan et al., 2019). The simulated mean mixing ratios of $\mathrm{OH}$ and $\mathrm{HO} 2$ radicals from the model in the present study were $\sim 1.6 \times 106$ moleculeÂůcm-3 and $\sim 3 \times 107$ moleculeÂůcm-3, which are comparable to the winter observations at Beijing, Tokyo, and New York (Kanaya et al., 2007; Ren et al., 2006; Ma et al., 2019), and lower than the measurement and simulation values in summer (e.g., July) or autumn (e.g., October to November) in the PRD region (Table S3 in the supplementary) (Hofzumahaus et al., 2009; Tan et al., 2019). Note that the variations of simulation results in the present study and those observation results in previous studies in PRD may be associated with differences in the levels of $\mathrm{O} 3$ and its precursors, different photolysis rates, and to a lesser extent, meteorological conditions (Hofzumahaus et al., 2009). The higher $\mathrm{OH}$ and $\mathrm{HO} 2$ mixing ratios were expected in summer and autumn than winter due to the stronger solar radiation and higher temperature, as well as the variations of $\mathrm{O} 3$ and its precursors in different sites, though the measurement of $\mathrm{OH} / \mathrm{HO} 2$ radicals has been very challenging, and significant uncertainties still exist in the measurement values of the radicals (Hofzumahaus et al., 2009; Tan et al., 2019). Furthermore, the comparison between the simulation of a box model and observation results suggested that the higher observed mixing ratios of

Printer-friendly version

Discussion paper 
$\mathrm{OH}$ and $\mathrm{HO} 2$ radicals were related to an unidentified source of $\mathrm{OH}$ at the backgarden site of PRD in summer of 2006, while the comparison between the observed $\mathrm{OH} / \mathrm{HO} 2$ variations and those calculated from the parameterization of $\mathrm{HOx}(\mathrm{HOx}=\mathrm{OH}+\mathrm{HO} 2)$ production and destruction indicated a missing $\mathrm{OH}$ source of 4-6 ppbvÂůh-1 and an unknown RO2 loss at the Heshan site in autumn of 2014." For details, please refer to Lines 380-403, Page 14 in the revised manuscript and Table S3 in the supplementary.

Interactive comment

2. The impact of $\mathrm{O} 3$ on GLY and MGLY is not discussed. Looking at Figure 2, it is obvious that GLY and MGLY must decrease at night. GLY and MGLY can also react with O3. This is likely an import process that reduces GLY and MGLY at night, in addition to SOA formation from gas-to-particle partitioning and aqueous reactions. Since GLY and MGLY data are collected throughout the entire 24 hour period, it might be interesting to see how well the box model predicts GLY and MGLY at night with different SOA modeling approaches. The nighttime behavior of GLY and MGLY and their roles in SOA formation is not as clear as the daytime and should not be ignored in this study. Reply: Thanks for the reviewer's comment. By investigating the relative contributions of different loss pathways of Gly and Mgly, it was found that during the daytime, the heterogeneous processes were the most important pathway for the destruction of Gly and Mgly (both with contributions of $\sim 62 \%$ ), followed by photolysis, $\mathrm{OH}$ reactions and dry deposition. We also examined the loss pathways of Gly and Mglys during nighttime, and only the heterogeneous processes make notable contribution to Gly and Mgly destruction, accounting for more than $90 \%$ of the total destruction (Table 2 as seen below), which was consistent with previous studies (Washenfelder et al., 2011; Gomez et al., 2015). The lower contributions of Gly and Mgly with radicals were mainly because of the low concentration of $\mathrm{OH}$ at night and their relatively lower reactivities with NO3 radical (Calvert et al., 2011; Mellouki et al., 2015). Table 2. The relative contributions of different loss pathways of Gly and Mgly at nighttime Loss pathyways Gly Mgly NO3,OH-reaction, \% 2.443 .56 dry deposition, \% 1.040 .74 dilution, \% 1.921 .60 heterogeneous a, \% Irreversible processes, \% 57.955 .9 Reversible processes, \% 36.738 .2 a Considered both irreversible and reversible parameterizations

Printer-friendly version

Discussion paper

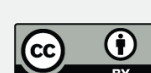


of the aerosol sinks (i.e., scenario 4 and M2).

Furthermore, we agree with the reviewer that Gly and Mgly may be also removed by the reaction with $\mathrm{O} 3$, and incorporation of more possible reaction mechanisms in addition to oxidation of Gly and Mgly by $\mathrm{NO} 3$ and $\mathrm{OH}$ radicals are reasonable. The previous study reported that kinetic data of $\mathrm{O} 3$ reactions with Gly and Mgly are of negligible atmospheric importance, with the reaction rate constants of $<3$ and $<6 \times 10-21$ cm3Âůmolecule-1Âůs-1, respectively, which are 6 order of magnitude lower than the reaction rate constants with $\mathrm{NO} 3$ (which $>1$ and $>2 \times 10-15 \mathrm{~cm} 3$ Âůmolecule-1Âus-1, respectively), and are 9 order of magnitude lower than the reaction rate constants with $\mathrm{OH}$ (which = 9 and $13 \times 10-12$ cm3Âůmolecule-1Âůs-1) (Mellouki et al., 2015). Due to the much lower reaction rates, we believe that the influence of $\mathrm{O} 3$ on the removal of Gly and Mgly was negligible. Furthermore, there were few parameterizations for the reaction mechanism of Gly/Mgly with $\mathrm{O} 3$ due to their low reaction rates with $\mathrm{O} 3$. Therefore, the present study did not include the pathway of $\mathrm{O} 3$ oxidation on Gly and Mgly. To explain the exclusion of the oxidation of Gly and Mgly by O3, and to clarify the contributions of different pathways to the removal of Gly and Mgly during nighttime, the following text has been added in the revised manuscript: "It should be noted that the oxidation of Gly and Mgly by $\mathrm{O} 3$ was not considered in this study as the reaction rate constants of Gly and Mgly with $\mathrm{O} 3$ are $<3$ and $<6 \times 10-21 \mathrm{~cm} 3$ Âůmolecule-1Âůs-1, respectively, which are 6 order of magnitude lower than the reaction rate constants with NO3 (which >1 and > $2 \times 10-15 \mathrm{~cm} 3$ Âumolecule-1Âus-1, respectively), and are 9 order of magnitude lower than the reaction rate constants with $\mathrm{OH}$ (9 and $13 \times 10-12$ cm3Âůmolecule-1Âůs-1 for the reactions of Gly and Mgly with O3, respectively) (Mellouki et al., 2015). Therefore, we believe that the influence of $\mathrm{O} 3$ on the removal of Gly and Mgly was negligible (Mellouki et al., 2015). Furthermore, there were few parameterizations for the reaction mechanism of Gly/Mgly with $\mathrm{O} 3$ due to their low reaction rates with $\mathrm{O} 3$. On the other hand, at nighttime, only the heterogenous processes made the main contribution to Gly and Mgly destruction, with contributions higher than $90 \%$ to the total destruction of Gly and Mgly at night (Table S9 in the supplementary), consis- 
tent with previous studies (Washenfelder et al., 2011; Gomez et al., 2015). The lower contributions of Gly and Mgly with radicals were mainly because of the low $\mathrm{OH}$ concentration at night and their relatively lower reactivities with NO3 radical (e.g., the reaction rate constants of Gly/Mgly with NO3 are $\sim 1000$ times lower than those with $\mathrm{OH}$ radical) (Calvert et al., 2011; Mellouki et al., 2015)." For details, please refer to Lines 544-562, Pages 19-20 in the revised manuscript and Table S9 in the supplementary.

3. The other issue that I think should be addressed is the primary emissions of GLY and MGLY, since not all are produced secondarily. It seems that no emissions of primary GLY and MGLY are included in the box model simulations. The authors might want to discuss how this omission can impact their conclusions. Reply: We thank the reviewer's valuable comment. Indeed, not all the Gly and Mgly in the atmosphere are produced secondarily. However, many previous studies have suggested that the dicarbonyls such as Gly and Mgly have limited primary sources except biomass burning and biofuel combustion (Grosjean et al., 2001; Zhang et al., 2016). The primary emissions of Gly and Mgly were much less significant than those secondarily from photochemical reactions (Lv et al., 2019). Fu et al. (2008) estimated that the primary emissions only accounted for about $4 \%$ and $17 \%$ to the total emissions of Mgly and Gly, respectively. To preliminarily estimate the contributions of primary and secondary sources to measured Gly and Mgly, a correlation-based source apportionment method suggested by previous studies was used, as described by equation 1 (Friedfeld et al., 2002; Yuan et al., 2013) . [dicarbonyls] $=\beta \_0+\beta \_1\left[\mathrm{C} \_2 \mathrm{H} \_2\right]+\beta \_2\left[0 \_3\right.$ ] (1) where $\beta 0, \beta 1$, and $\beta 2$ are the coefficients derived from the linear regression analysis. For every unit increase in $\mathrm{C} 2 \mathrm{H} 2$ concentration there is a $\beta 1$ unit increase in dicarbonyls. Similarly, for every unit increase in $\mathrm{O} 3$ concentration there is a $\beta 2$ unit increase in dicarbonyls. $\beta \_0$ can be considered the background carbonyls level (in units of ppbv). Relative contributions from primary emissions, secondary formation, and background dicarbonyl concentrations can be computed according to the tracer concentrations and corresponding $\beta$ values by the following equations: $\mathrm{P} \_$primary $=\left(\beta \_1\left[\mathrm{C} \_2 \mathrm{H} \_2\right] \mathrm{i}\right) /\left(\left(\beta \_0+\beta \_1\left[\mathrm{C} \_2 \mathrm{H} \_2\right.\right.\right.$ ] $\left.\left.\mathrm{i}+\beta \_2\left[\mathrm{O} \_3\right] \mathrm{i}\right)\right) \times 100 \%$ (2) $\mathrm{P} \_$secondary $=\left(\beta \_2\left[\mathrm{O} \_3\right] \mathrm{i}\right) /\left(\beta \_0+\beta \_1\left[\mathrm{C} \_2 \mathrm{H} \_2\right] \mathrm{i}+\beta \_2\right.$ 
[O_3 ]i) $) \times 100 \%$ (3) P_background $=\beta \_0 /\left(\left(\beta \_0+\beta \_1\left[\mathrm{C} \_2 \mathrm{H} \_2\right] \mathrm{i}+\beta \_2\left[\mathrm{O} \_3\right.\right.\right.$ ]i) $) \times 100 \%$ (4) Table 3 shows linear regression coefficients and relative source contributions of Gly and Mgly. It was found that the contributions from primary sources is significantly lower than those from secondary sources $(96.14 \%$ and $96.44 \%$ for Gly and Mgly, respectively), confirming that Gly and Mgly in the present study were mostly related to secondary formation.

Interactive

comment

Table 3. Linear regression coefficients and relative contributions of primary, secondary, and background sources of Gly and Mgly. Linear regression coefficients Source Contribution $\beta \_0 \beta \_1 \beta \_2$ Background Primary Secondary R Gly $0.0010 .0660 .0420 .40 \%$ $3.46 \% 96 . \overline{1} 4 \% 0.77$ Mgly $0.0020 .1080 .0810 .05 \% 3.51 \% 96.44 \% 0.75$

To highlight the potential significance of secondary formation on the abundance of Gly and Mgly, the following text was added: "It has been well documented that Gly and Mgly have limited primary sources except biomass burning and biofuel combustion (Grosjean et al., 2001; Zhang et al., 2016). Furthermore, the primary emissions of Gly and Mgly were much less significant than those secondarily from photochemical reactions (Lv et al., 2019). Fu et al. (2008) estimated that primary emissions only accounted for about $4 \%$ and $17 \%$ to the total emissions of Mgly and Gly, respectively." For details, please refer to Lines 80-85, Page 3 in the revised manuscript.

Furthermore, the following text for the preliminary estimation of primary and secondary sources of Gly and Mgly was added in the revised manuscript: "In this study, the simulated Gly and Mgly were secondarily formed from the oxidation of their VOC precursors. Therefore, before the comparison between the simulation and observation results, the contributions of primary and secondary sources to the measured Gly and Mgly were preliminarily estimated by a correlation-based source apportionment method suggested by previous studies (Friedfeld et al., 2002; Yuan et al., 2013). Table S5 in the supplementary shows linear regression coefficients and relative source contributions of Gly and Mgly. It was found that the contributions from primary sources (3.46 \% and $3.51 \%$ for Gly and Mgly, respectively) were significantly lower than those

Printer-friendly version

Discussion paper 
from secondary sources (96.14\% and $96.44 \%$, respectively), confirming that observed Gly and Mgly in the present study were mostly related to secondary formation." For details, please refer to Lines 440-450, Page 16 in the revised manuscript and Table S5 in the supplementary.

4. Modeling SOA formation from GLY and MGLY using the Master Chemical Mechanism has been discussed in a more complete regional air quality model that considers the transport and emissions of GLY and MGLY(Li et al. 2015). Another paper that discusses the importance of the GLY and MGLY on SOA formation is Ying et al 2015, which shows that including SOA from uptake of GLY/MGLY leads to significant improvement in predicated SOA in these southeast United Stated. These references appear to be neglected by the authors. Reply: Thanks for the reviewer's suggestions. It has been revised accordingly in the revised manuscript. "For example, Li et al (2015) constructed a Master Chemical Mechanism with an equilibrium partitioning module and coupled it in a Community Air Quality Model (CMAQ) to predict the regional concentrations of SOA from VOCs in the eastern United States (U.S). It was found that those SOA formed from Gly and Mgly were accounted for more than 35\% of total SOA. Similarly, Ying et al. (2015) used a modified SAPRC-11 (S11) photochemical mechanism, considering the surface-controlled reactive uptake of Gly and Mgly, and incorporated the mechanism in the CMAQ model to simulate ambient SOA concentrations during summer in the eastern U.S. The results showed that the uptake of Gly and Mgly resulted in the significant improvement in predicated SOA concentration, and the aerosol surface uptake of isoprene-generated Gly, Mgly and epoxydiol accounted for more than $45 \%$ of total SOA." For details, please refer to Lines 68-78, Page 3 in the revised manuscript.

References: Calvert, J., Mellouki, A., Orlando, J., 2011. Mechanisms of atmospheric oxidation of the oxygenates. OUP USA. Creasey, D.J., Heard, D.E., Lee, J.D., 2001. $\mathrm{OH}$ and $\mathrm{HO} 2$ measurements in a forested region of north-western Greece. Atmos. Environ. 35(27), 4713-4724. Friedfeld, S., Fraser, M., Ensor, K., Tribble, S., Rehle, D., Leleux, D. and Tittel, F., 2002. Statistical analysis of primary and secondary atmo- 
spheric formaldehyde. Atmos. Environ. 36(30), 4767-4775. Fu, T.-M., Jacob, D.J., Wittrock, F., Burrows, J.P., Henze, D.K., 2008. Global budgets of atmospheric glyoxal and methylglyoxal, and implications for formation of secondary organic aerosols. J. Geophys. Res. Atmos. 113(D15). Fuchs, H., Hofzumahaus, A., Rohrer, F., Bohn, B., Brauers, T., Dorn, H. P., Haseler, R., Holland, F., Kaminski, M., Li, X.,Lu, K., Nehr, S., Tillmann, R., Wegener, R., and Wahner, A., 2013. Experimental evidence for efficient hydroxyl radical regeneration in isoprene oxidation, Nat. Geosci., 6, 1023-1026. Garcia, AR, Volkamer, R, Molina, LT, Molina, MJ, Samuelson, J, Mellqvist, J, Galle, B, Herndon, SC, Kolb, CE. 2005. Separation of emitted and photochemical formaldehyde in Mexico City using a statistical analysis and a new pair of gas-phase tracers. Atmos. Chem. Phys Discussions, European Geosciences Union, 2005, 5 (6),11583-11615. Gomez, M.E., Lin, Y., Guo, S., Zhang, R., 2015. Heterogeneous chemistry of glyoxal on acidic solutions. An oligomerization pathway for secondary organic aerosol formation. J. Phys. Chem. A. 119(19). 4457-4463. Grosjean, D, Grosjean, E, Gertler, A., 2001. On-road emissions of carbonyls from light-duty and heavy-duty vehicles. Environ. Sci. Technol. 351, 45-53. Hofzumahaus, A., Rohrer, F., Lu, K.D., Bohn, B., Brauers, T., Chang, C.C., Fuchs, H., Holland, F., Kita, K., Kondo, Y., Li, X., Lou, S.R., Shao, M., Zeng, L., Wahner, A., Zhang, Y.H., 2009. Amplified trace gas removal in the troposphere. Science. 324, 1702-1704. Huang, W.W., Zhao, Q.Y., Liu, Q., Chen, F., He, Z.R., Guo, H., Ling, Z.H., 2020. Assessment of atmospheric photochemical reactivity in the Yangtze River Delta using a photochemical box model. Atmos. Res. 245, 105088. Kanaya, Y., Cao, R., Akimoto, H., Fukuda, M., Komazaki, Y., Yokouchi, Y., Koike, M., Tanimoto, H., Takegawa, N., Kondo, Y., 2007. Urban photochemistry in central Tokyo: 1. Observed and modeled $\mathrm{OH}$ and $\mathrm{HO} 2$ radical concentrations during the winter and summer of 2004. J. Geophys. Res. Atmos. 112(D21). Li, J., Cleveland, M., Ziemba, L. D., Griffin, R. J., Barsanti, K. C., Pankow, J. F., 2015. Modeling regional secondary organic aerosol using the Master Chemical Mechanism. Atmos. Environ. 102, 52-61. Li, X., Rohrer, F, Brauers, T, Hofzumahaus, A, Lu, K, Shao, $\mathrm{M}$, Zhang, $\mathrm{YH}$, Wahner, A. 2014. Modeling of $\mathrm{HCHO}$ and $\mathrm{CHOCHO}$ at a semi-rural 
site in southern China during the PRIDE-PRD2006 campaign. Atmos. Chem. Phys. 1422, 12291-12305. Ling, Z. H., Guo, H., Lam, S. H. M., Saunders, S. M., Wang, T., 2014. Atmospheric photochemical reactivity and ozone production at two sites in Hong Kong: Application of a master chemical mechanism-photochemical box model. J. Geophys. Res. Atmos. 119(17), 10567-10582. Liu, X., Lyu, X., Wang, Y., Jiang, F., Guo, H., 2019. Intercomparison of $\mathrm{O} 3$ formation and radical chemistry in the past decade at a suburban site in Hong Kong. Atmos. Chem. Phys. 19, 5127-5145. Liu, Z., Wang, Y., Vrekoussis, M., Richter, A., Wittrock, F., Burrows, J. P., Chen, C., 2012. Exploring the missing source of glyoxal $(\mathrm{CHOCHO})$ over China. Geophys. Res. Lett. 39(10). Lv, S., Gong, D., Ding, Y., Lin, Y., Wang, H., Ding, H., 2019. Elevated levels of glyoxal and methylglyoxal at a remote mountain site in southern China: Prompt in-situ formation combined with strong regional transport. Sci. Total Environ. 672, 869-882. Ma, X., Tan, Z., Lu, K., Yang, X., Liu, Y., Li, S., Li, X., Chen, S., Novelli, A., Cho, C., Zeng, L., 2019. Winter photochemistry in Beijing: Observation and model simulation of $\mathrm{OH}$ and $\mathrm{HO} 2$ radicals at an urban site. Sci. Total Environ. 685, 85-95. Madronich, S., Flocke, S., 1997. Theoretical estimation of biologically effective UV radiation at the Earth's surface. Solar ultraviolet radiation. Mellouki, A., Wallington, T.J., Chen, J., 2015. Atmospheric chemistry of oxygenated volatile organic compounds: impacts on air quality and climate. Chem. Rev. 10, 3984-4014. Nan, J., Wang, S., Guo, Y., Xiang, Y., Zhou, B., 2017. Study on the daytime $\mathrm{OH}$ radical and implication for its relationship with fine particles over megacity of Shanghai, China. Atmos. Environ. 154, 167-178. Ren, X., Brune, W.H., Mao, J., Mitchell, M.J., Lesher, R.L., Simpas, J.B., Metcalf, A.R., Schwab, J.J., Cai, C., Li, Y., Demerjian, K.L., 2006. Behavior of OH and $\mathrm{HO} 2$ in the winter atmosphere in New York City. Atmos. Environ. 40, 252-263. Tan, Z., Lu, K., Hofzumahaus, A., Fuchs, H., Bohn, B., Holland, F., Liu, Y., Rohrer, F., Shao, M., Sun, K. and Wu, Y., 2019. Experimental budgets of $\mathrm{OH}, \mathrm{HO} 2$, and $\mathrm{RO} 2$ radicals and implications for ozone formation in the Pearl River Delta in China 2014. Atmos. Chem. Phys, 19(10). Volkamer, R., San Martini, F., Molina, L. T., Salcedo, D., Jimenez, J. L., Molina, M. J., 2007. A missing sink for gas-phase glyoxal in Mexico 
City: Formation of secondary organic aerosol. Geophys. Res. Lett. 34(19), 255-268. Wang, Y., Guo, H., Zou, S.C., Lyu, X.P., Ling, Z.H., Cheng, H.R., Zeren, Y.Z., 2018. Surface $\mathrm{O} 3$ photochemistry over the South China Sea: application of a near-explicit chemical mechanism box model. Environ. Pollution. 234, 155-166. Washenfelder, R.A., Young, C.J., Brown, S.S., Angevine, W.M., Atlas, E.L., Blake, D.R., Bon, D.M., Cubison, M.J., De Gouw, J.A., Dusanter, S., Flynn, J., 2011. The glyoxal budget and its contribution to organic aerosol for Los Angeles, California, during CalNex 2010. J. Geophys. Res. Atmos. 116(D21). Xue, L. K., Wang, T., Gao, J., Ding, A. J., Zhou, X. H., Blake, D. R., Wang, X. F., Saunders, S. M., Fan, S. J., Zuo, H. C., Zhang, Q. Z., Wang, W. X., 2014a. Ground-level ozone in four Chinese cities: precursors, regional transport and heterogeneous processes. Atmos. Chem. Phys. (14)23, 13175-13188. Xue, L. K., Wang, T., Louie, P. K. K., Luk, C. W. Y., Blake, D. R., Xu, Z., 2014b. Increasing external effects negate local efforts to control ozone air pollution: a case study of Hong Kong and implications for other Chinese cities. Environ. Sci. Technol. 48(18), 10769-10775. Yang, X., Xue, L.K., Wang, T., Wang, X.F., Gao, J., Lee, S.C., Blake, D.R., Chai, F.H., Wang, W.X., 2018. Observations and explicit modeling of summertime carbonyl formation in Beijing: identification of key precursor species and their impact on atmospheric oxidation chemistry. J. Geophys. Res. Atmos. 123, 1426-1440. Ying, Q., Li, J., Kota, S. H.,2015. Significant contributions of isoprene to summertime secondary organic aerosol in eastern United States. Environ. Sci. Technol. 49(13), 7834-7842. Yuan, B., Hu, W.W., Shao, M., Wang, M., Chen, W.T., Lu, S.H., Zeng, L.M., Hu, M., 2013. VOC emissions, evolutions and contributions to SOA formation at a receptor site in eastern China. Atmos. Chem. Phys. 13, 8815-8832. Zhang, Y. L., Wang, X. M., Sheng, W., Herrmann, H., Yang, W. Q., Huang, X. Y., Zhou, Z., Huang, Z. H., He, Q. F., George, C., 2016. On-road vehicle emissions of glyoxal and methylglyoxal from tunnel tests in urban Guangzhou, China. Atmos. Environ. 127, $55-60$. 
https://www.atmos-chem-phys-discuss.net/acp-2020-212/acp-2020-212-AC2supplement.pdf

ACPD

Interactive comment on Atmos. Chem. Phys. Discuss., https://doi.org/10.5194/acp-2020-212, 2020.

Interactive

comment 